\title{
c-Fos or pERK, Which is a Better Marker for Neuronal Activation and Central Sensitization After Noxious Stimulation and Tissue Injury?
}

\author{
Yong-Jing Gao* and Ru-Rong Ji*
}

\author{
Pain Research Center, Department of Anesthesiology, Brigham and Women's Hospital and Harvard Medical School, \\ Boston, Massachusetts 02115, USA
}

\begin{abstract}
Fos, the protein of the protooncogene $c$-fos, has been extensively used as a marker for the activation of nociceptive neurons in the spinal cord for more than twenty years since Hunt et al. first reported that peripheral noxious stimulation to a hind paw of rats leads to a marked induction of c-Fos in superficial and deep dorsal horn neurons in 1987. In 1999, Ji et al. reported that phosphorylated extracellular signal-regulated kinase (pERK) is specifically induced by noxious stimulation in superficial dorsal horn neurons. Accumulating evidence indicates that pERK induction or ERK activation in dorsal horn neurons is essential for the development of central sensitization, increased sensitivity of dorsal horn neurons that is responsible for the generation of persistent pain. Further, molecular mechanisms underlying ERKmediated central sensitization have been revealed. In contrast, direct evidence for c-Fos-mediated central sensitization is not sufficient. After a noxious stimulus (e.g., capsaicin injection) or tissue injury, c-Fos begins to be induced after 30-60 minutes, whereas pERK can be induced within a minute, which can correlate well with the development of pain hypersensitivity. While c-Fos is often induced in the nuclei of neurons, pERK can be induced in different subcellular structures of neurons such as nuclei, cytoplasma, axons, and dendrites. pERK can even be induced in spinal cord microglia and astrocytes after nerve injury. In summary, both c-Fos and pERK can be used as markers for neuronal activation following noxious stimulation and tissue injury, but pERK is much more dynamic and appears to be a better marker for central sensitization.
\end{abstract}

\section{INTRODUCTION}

The protooncogene $c$-fos, can be rapidly induced within minutes by stimulation of a neurotransmitter [1], therefore, is called the immediate early gene. As the protein product of $c$ fos, c-Fos can form a complex with Jun, another oncogene protein, and this complex binds to the AP-1 DNA site to induce gene transcription. Therefore, c-Fos is involved in signal transduction cascade that links extracellular events to intracellular adaptations [2, 3]. To determine if c-Fos expression can be used a marker for neuronal activation in the brain, Morgan et al. mapped patterns of c-Fos expression in the central nervous system after seizure [4]. Further, Hunt et al. examined c-Fos expression in the spinal cord following low- and high-threshold sensory stimuli to a hindpaw of rats and made several important findings. First, the basal expression of c-Fos is very low. Second, high-threshold noxious stimuli can induce a very dramatic increase of c-Fos expression in spinal cord dorsal horn neurons. Third, the pattern of c-Fos expression is topographically correlated with that of primary afferent projection from the hindpaw [5]. Since then, c-Fos has been widely used as a tool for the study of neural correlates of nociception [6-8] and as a neuronal marker for testing the efficacy of analgesic compounds $[9,10]$. There are several advantages of c-Fos as a marker for neuronal activation after noxious stimulation

*Address correspondence to these authors at the Department of Anesthesiology, Brigham and Women's Hospital, 75 Francis Street, Medical Research Building, Room 604, Boston, MA 02115, USA; Tel: (617) 732-5500 Ext 32363; Fax: (617) 730-2801;

Email: yjgao@partners.org and rrji@zeus.bwh.harvard.edu and tissue injury. First, c-Fos expression after noxious stimuli is specific, rapid, and robust. Second, c-Fos immunohistochemistry is relatively easy to perform and quantify. Third, c-Fos is expressed only in nuclei, and therefore, c-Fos immunohistochemistry can be performed in combination with tract-tracing procedures to identify the properties of c-Fos labeled neurons. However, the direct role of c-Fos in pain regulation remains to be investigated.

The extracellular signal-regulated kinase (ERK, including ERK1 and ERK2), is a member of mitogenactivated protein kinase (MAPK) family. ERK is activated via phosphorylation by its upstream kinase MEK (MAP kinase or ERK kinase). ERK activation requires a cascade that involves sequential activation of Ras, Raf, and MEK [11]. Upon activation, phosphorylated ERK (pERK) can be translocated into the nucleus to activate several transcriptional factors, such as cAMP-response element binding protein (CREB) that is required for the transcription of many neuronal genes and long-term synaptic plasticity [12]. Although early studies indicated a critical role of ERK in regulating mitosis, proliferation, differentiation, and survival of mammalian cells during development [11], recent studies showed that the ERK is involved in neural and synaptic plasticity underlying learning and memory and pain hypersensitivity $[13,14]$. In 1999, Ji et al. used immunohistochemistry to examine pERK expression in the spinal cord following peripheral sensory stimuli to a hindpaw [15]. Like c-Fos expression, pERK expression is also very robust and requires high-threshold noxious stimuli. Topographically, pERK expression is very specific and predominantly induced in dorsal horn neurons of the medial superficial spinal cord on the stimulated side where primary nociceptive 
afferents from the hindpaw terminate (Fig. 1) [15]. Furthermore, analgesic compounds can suppress pERK expression or ERK activation [16-18]. Therefore, pERK expression can also been used as a marker for the activation of dorsal horn neurons following nociceptive activity. Unlike c-Fos, pERK expression is much more rapid and dynamic. Importantly, the role of pERK in central sensitization has been clearly demonstrated, thanks to specific inhibitors of the ERK pathway $[15,18]$. Central sensitization, i.e. hyperactivity of nociceptive neurons in the central nervous system, especially in spinal cord dorsal horn neurons, plays an essential role in the development and maintenance of persistent pain $[14,19]$. Thus, it is extremely important to find molecular markers for central sensitization.

In this review, we compare the strengths and weaknesses of c-Fos and pERK as markers for neuronal activation and central sensitization from the following aspects (Table 1).

\section{STIMULUS-DEPENDENT EXPRESSION OF C-FOS AND PERK IN SPINAL CORD DORSAL HORN NEU- RONS}

Under normal conditions, c-Fos and pERK are rarely expressed in the spinal cord. Innocuous (non-noxious)

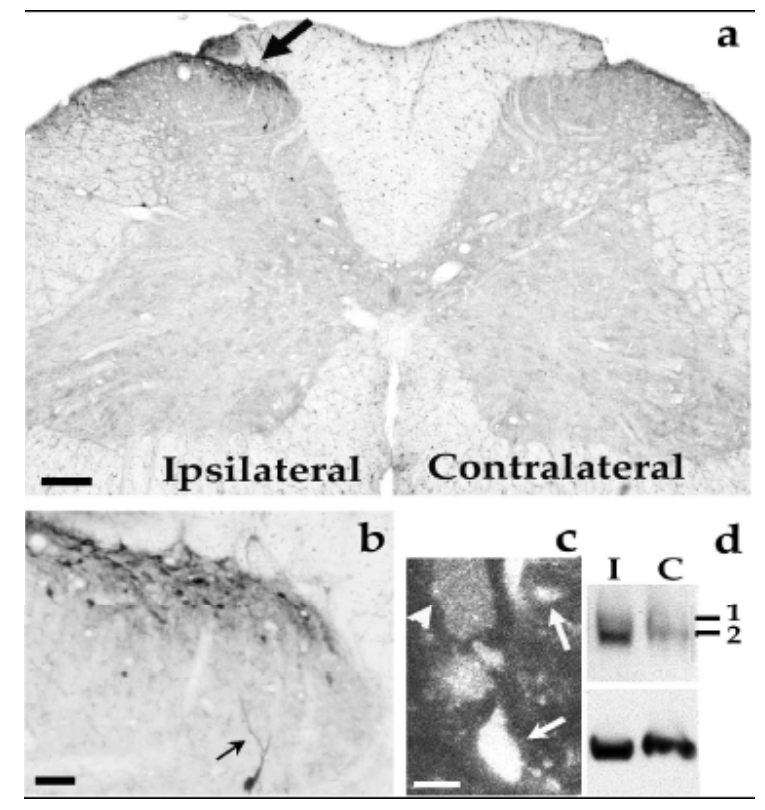

Fig. (1). Induction of ERK phosphorylation (pERK) in the ipsilateral spinal cord dorsal horn by intraplantar capsaicin injection. (a) Transverse section of the L5 lumbar spinal cord showing increased pERK immunoreactivity (IR) in the ipsilateral medial superficial dorsal horn (arrow) 2 min after a capsaicin injection $(75 \mu \mathrm{g})$ into a hindpaw. Scale, 200 $\mu \mathrm{m}$. (b) High magnification image from (a) showing pERK-IR in many small postsynaptic neurons in the superficial dorsal horn and a solitary deeper neuron. Arrow indicates a dendrite. Scale, $50 \mu \mathrm{m}$. (c) Confocal image showing induced pERK-IR in cytoplasm (arrow head) and nucleus (arrows). Scale, $5 \mu \mathrm{m}$. (d) Western blot obtained from ipsilateral (I) and contralateral (C) spinal dorsal horn indicating that ERK1/2 especially ERK2 are phosphorylated after capsaicin stimulation. Bottom bands are controls for total ERK2. 1 and 2 indicate pERK1 and pERK2, respectively. Reproduced from Nature Neuroscience $(2: 1114-1119,1999)$ with permission. stimuli, such as light touch, warm water, or $A \beta$ fiber activation normally do not induce the expression of c-Fos and pERK. But they can be induced in dorsal horn neurons by various types of noxious stimuli, including thermal, mechanical, chemical (e.g., capsaicin, formalin, bee and scorpion venom), and electrical stimuli [5, 7, 20]. The correlation of c-Fos expression and the stimulus intensity has been widely investigated. In many conditions, increased intensity of stimulation is correlated with increased c-Fos expression. Abbadie et al. reported that there is no or little Fos expression in the lumbar spinal cord when the paw is at temperatures between 15 and $-10^{\circ} \mathrm{C}$. The threshold to induce c-Fos expression is $-15^{\circ} \mathrm{C}$. The number of Fos- immunoreactive (IR) neurons increases with decreased temperature $\left(-15\right.$ to $\left.-20^{\circ} \mathrm{C}\right)$ [21]. Traub et al. showed that repetitive colorectal distention to 20,40 or $80 \mathrm{~mm} \mathrm{Hg}$ induces c-Fos expression in dorsal horn neurons. However, $80 \mathrm{~mm} \mathrm{Hg}$ distension results in significantly more Fos-IR nuclei than 20 or $40 \mathrm{~mm} \mathrm{Hg}$ distension [22]. Subcutaneous injection of chemicals, such as capsaicin, carrageenan, formalin induces dose-dependent c-Fos expression in the spinal cord dorsal horn [23-25].

pERK expression is also intensity dependent. Immersion of a rat's hindpaw into hot water induces pERK expression around the temperature of $45^{\circ} \mathrm{C}$. The number of pERK-IR neurons increases with increasing temperature $\left(45-55^{\circ} \mathrm{C}\right)$ [15]. In a spinal slice preparation, electrical stimulation of the dorsal root with low intensity (A $\beta$-fiber activation) does not induce pERK expression. When the intensity is increased to activate $\mathrm{A} \Delta$-fibers, pERK begins to be induced in dorsal horn neurons. The strongest pERK expression is induced when the intensity is further increased to activate C-fibers [15]. As stimulus intensity increases, not only the number of c-Fos- and pERK-IR neurons increases, but also the territories expressing c-Fos and pERK expand from superficial to the deep dorsal horn $[6,15,26]$. Further, an increase in the duration of stimulus also increases Fos and pERK expression in dorsal horn neurons [6, 26, 27].

Although c-Fos and pERK are induced by high-intensity noxious stimuli in normal conditions, they can also be induced by low-intensity innocuous stimuli under pathological condition. For example, after nerve injury, lowintensity stimuli can induce Fos expression [28-30] and pERK expression [31, 32] in dorsal horn neurons. Repeated innocuous stroke or brush on inflamed paw induces spinal c-Fos expression [33, 34]. Movement of the inflamed joint but not non-inflamed joint also increases pERK expression in dorsal horn neurons [35].

Taken together, types of stimuli that can induce c-Fos and pERK expression are quite similar. However, the duration of noxious stimulation is different. For example, a very brief noxious stimulation ( $<10$ seconds) does not induce pERK [27], even thought it is sufficient to induce c-Fos expression in dorsal horn neurons [5]. Thus, it is likely that pERK is selectively induced by noxious stimuli that may cause persistent changes in pain sensitivity. In contrast, a non-noxious visceral stimulus, such as repetitive colorectal distention with a low pressure $(20 \mathrm{~mm} \mathrm{Hg})$ is sufficient to induce c-Fos expression [22]. A continuous non-noxious input, generated by walking in a rotarod, is also able to 
Table 1. Comparison of Different Features of c-Fos and pERK Expression and their Roles in Pain Regulation

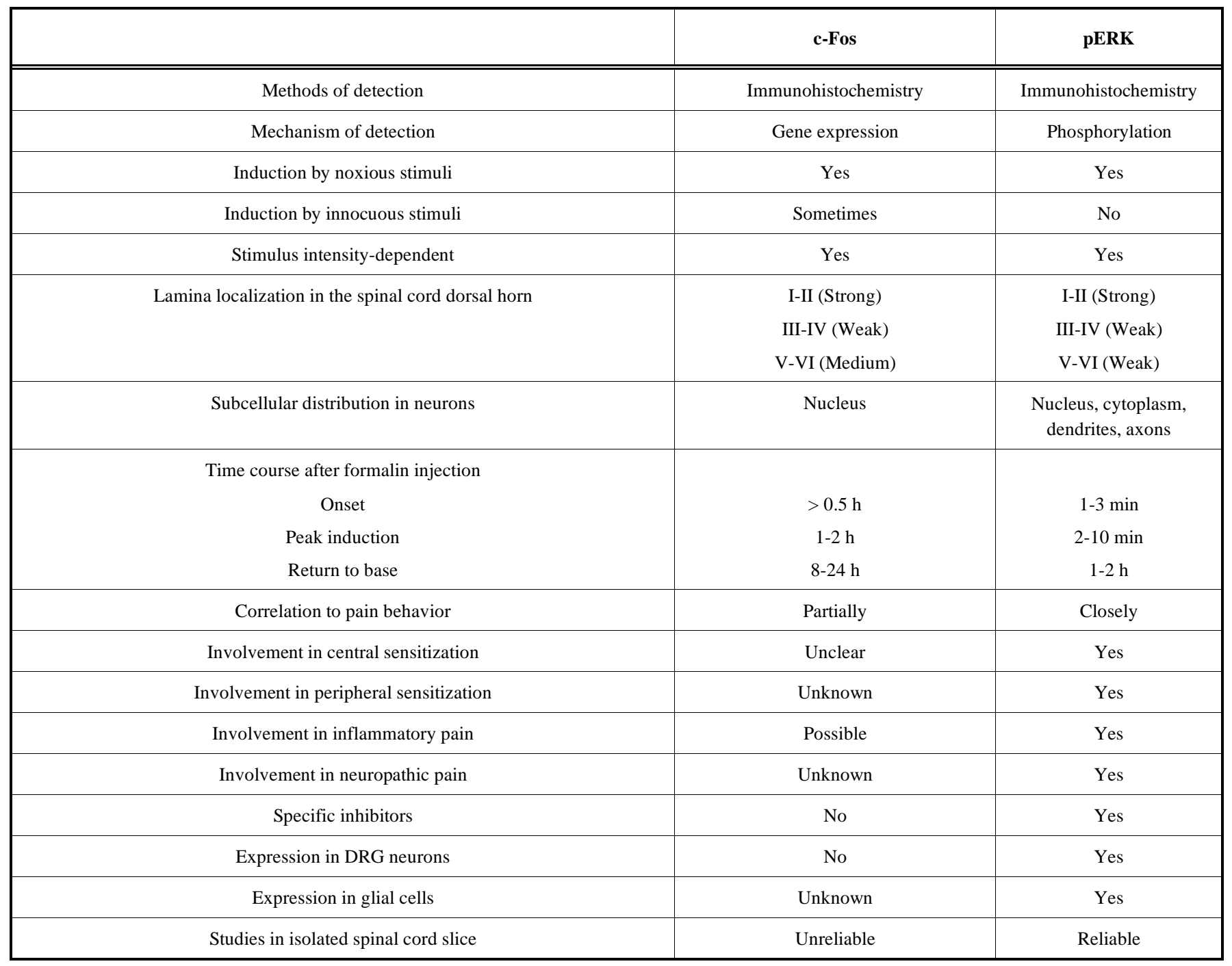

induce c-Fos in spinal interneurons [36]. Therefore, c-Fos induction is not highly nociceptive-specific.

\section{DISTINCT TIME COURSES AND DISTRIBUTION PATTERNS OF C-FOS AND PERK EXPRESSION IN THE SPINAL CORD AFTER NOXIOUS STIMULI}

The time courses of c-Fos and pERK induction following a noxious stimulation are quite different. As an immediateearly gene, $c$-fos mRNA can be activated within minutes of stimulation, with a peak accumulation in 30 minutes [37]. But the expression of c-Fos protein is significantly delayed. After an acute noxious stimulation, such as hindpaw formalin injection, c-Fos expression begins at $0.5 \mathrm{~h}$, peaks at 1-2 $\mathrm{h}$, and returns to basal levels after 8-24 $\mathrm{h}[5,9,38]$ (Table 1). Compared to c-Fos expression, pERK expression or ERK phosphorylation is much faster. Following formalin injection, pERK increase reaches to a peak within $3 \mathrm{~min}$ [15]. After capsaicin injection, pERK begins to increase within $1 \mathrm{~min}$, peaks in $2-5 \mathrm{~min}$, declines to $50 \%$ peak level at $10 \mathrm{~min}$, and returns to base level in $2 \mathrm{~h} \mathrm{[15].}$

The lamina distribution patterns of c-Fos and pERK in the spinal cord after an acute noxious stimulation are largely similar. Fos-IR neurons are mostly found in laminae I-II, with a few in laminae III-IV and some in laminae V-VI [5, 7]. Most pERK-IR neurons are observed in the laminae I-II, with a few in laminae III-VI but none in the ventral horn and contralateral side (Fig. 1). But the subcellular distribution of c-Fos and pERK are very different. While c-Fos is almost exclusively expressed in nuclei, pERK can be found in different subcellular localization, such as cytoplasma, nuclei, dendrites, and axons (Fig. 1, Table 1).

Unlike c-Fos, pERK is also induced in primary sensory neurons in the dorsal root ganglion (DRG). Capsaicin induces pERK expression in small-to-medium diameter DRG neurons in a similar time course as in the spinal cord [39]. Intraplantar capsaicin also induces pERK in nerve fibers of the epidermis within $2 \mathrm{~min}[39,40]$. Therefore, pERK can also serve as a marker for the activation of primary sensory neurons both in cell bodies and axons.

In addition, c-Fos and pERK are induced in pathological conditions. Sciatic nerve transaction produces persistent c-Fos expression in spinal cord neurons [7, 41]. Spinal nerve ligation (SNL) also induces sustained pERK expression in the spinal cord. It is of great interest that pERK is induced in 
different cell types at different times after nerve injury [42]. Immediately after nerve injury ( $10 \mathrm{~min}$ to $6 \mathrm{~h}$ ), pERK is induced in dorsal horn neurons. This initial neuronal induction of $p E R K$ results from nerve injury-induced spontaneous discharge. Two days after injury, pERK is switched to microglia cells. Three weeks later, pERK is increased in astrocytes. Sequential induction of pERK in different cell types is important for neuropathic pain development at different phases [42].

\section{INDUCTION OF PERK IN ISOLATED SPINAL CORD SLICES}

Almost all spinal cord studies on c-Fos are performed in intact animals in vivo. Isolated spinal cord slice preparation ex vivo offers a great model to study spinal cord mechanisms, because in this model, (1) drug application is much more convenient and accurate, and (2) many spinal cord slices $(400-600 \mu \mathrm{m})$ can be prepared from a spinal cord segment (L3-L5). Therefore, spinal slices are very convenient for testing the effects of analgesics in spinal cord neurons. Bath application of capsaicin to spinal slices will activate C-fiber terminals to release neurotransmitters, activating ERK in postsynaptic neurons. Therefore, numerous pERK-IR neurons can be rapidly found in superficial dorsal horn neurons after capsaicin application (Fig. 2) [43, 44]. Using this model, we have identified multiple receptors and protein kinases that are involved in pERK induction in dorsal horn neurons [17, 43]. We have also demonstrated that morphine and cannabinoid can potently inhibit pERK induction in this model [43]. Therefore, rapid induction of pERK by bath application capsaicin on spinal cord slices is a useful method for the screening of potential analgesic drugs [45]. pERK induction has also been examined in spinal slice with dorsal root attached. Electrical stimulation of the dorsal root at C-fiber intensity produces a robust pERK induction in superficial dorsal horn neurons $[15,46]$. However, it is very difficult to study c-Fos expression in isolated spinal cord slices, since the slice preparation per se will induce very high basal expression of c-Fos in dorsal horn neurons. In contrast, basal expression of pERK is very low after 3-hour perfusion, because pERK induction in spinal neurons during slice preparation is very transient.

\section{CORRELATION BETWEEN c-FOS, PERK AND PAIN- RELATED BEHAVIOR}

Most stimuli that lead to Fos expression cause pain-like behaviors in animals. Also, most manipulations that affect pain-related behaviors similarly modify the expression of c-Fos [7, 8]. For example, reductions of c-Fos expression are found after administration of analgesic drugs, non-steroidal anti-inflammatory drugs, as well as compounds that interfere with nociceptive processing at the spinal cord level, such as NMDA and AMPA/KA receptor antagonists, $\mathrm{GABA}_{B}$ agonist, serotonin antagonists, and cannabinoids [7]. In addition, some manipulations that produce analgesia, such as electroacupuncture also reduce spinal c-Fos expression [7].

However, c-Fos expression and nociceptive behavior are not closely correlated. First, the time course of c-Fos expression and noxious behavior are not consistent. For instance, most noxious stimuli, such as capsaicin, formalin, heat or cold, give essentially instant pain, but it takes at least
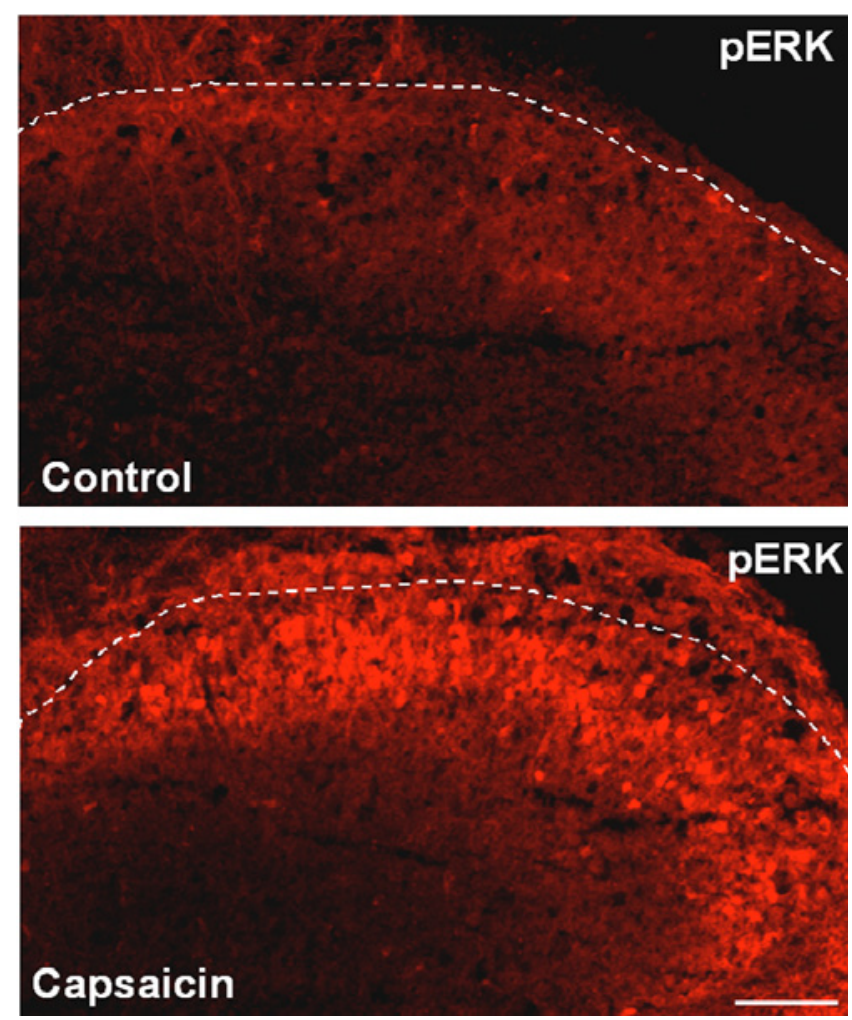

Fig. (2). Induction of pERK in the superficial dorsal horn by bath application of capsaicin to isolated spinal cord slices. Transverse spinal cord slices $(600 \mu \mathrm{m}$ in thickness) were cut on a vibrating microslicer, superfused with capsaicin $(3 \mathrm{mM})$ for $5 \mathrm{~min}$, and fixed with $4 \%$ paraformaldehyde for $30 \mathrm{~min}$. The slices were then cut into thin sections $(15 \mu \mathrm{m})$ in a cryostat and processed for pERK immunohistochemistry. See Kawasaki et al. (2004) for more details. White lines indicate the borders of the gray matter of the spinal cord. Scale, $100 \mu \mathrm{m}$.

$30 \mathrm{~min}$ for c-Fos to appear. Second, neuropathic pain behaviors can persist for many weeks, whereas Fos induction often fades within 2 weeks [47-49]. Third, intrathecal delivery of $c$-fos antisense oligonucleotides reduce c-Fos expression, but result in pain hypersensitivity in the formalin model $[50,51]$.

pERK activation appears to be more closely correlated with pain-related behavior. For example, intraplantar injection of capsaicin induces an intense but short-lived spontaneous pain behavior in the first 3-5 minutes. Capsaicin also produces heat hyperalgesia for 2 hours [39, 40]. Consistently, capsaicin-induced pERK expression begins within a minute and recovers in 2 hours [15]. After nerve injury, pERK induction in spinal cord microglia, in the early stage, is correlated with the development of neuroapthic pain. Whereas pERK expression in astrocytes, in the late stage, is correlated with the maintenance of neuropathic pain [42].

Most importantly, direct inhibition of pERK induction by specific MEK inhibitor U0126 or PD98059 can reduce painrelated behaviors induced by formalin [15], complete Freund's adjuvant $[52,53]$, bee venom [54], scorpion venom [55], and spinal nerve ligation [42, 56]. Additionally, indirect inhibition of pERK expression by metabotropic glutamate 
subtypes $1 / 5$ antagonist was shown to reduce formalininduced pain behavior [18].

\section{THE ROLE OF C-FOS AND PERK IN CENTRAL SENSITIZATION}

Due to the lack of specific c-Fos inhibitor, the role of cfos in pain regulation was investigated using c-fos antisense oligodeoxynucleotides (AS-ODNs). Although intrathecal injections of c-fos AS-ODNs can inhibit c-fos protein expression after noxious stimuli [50, 51, 57-60], the effects on pain behavior are inconsistent. Several studies showed that c-fos AS-ODNs decrease formalin-induced nociceptive behavior [61], bee venom-induced nociceptive behavior [60], adjuvant-induced thermal hyperalgesia [59]. On the contrary, Hunter et al. and Ibrahim et al. reported that c-fos AS-ODNs increase formalin-induced pain $[50,51]$. The mechanisms underlying c-Fos-mediated pain regulation are largely unknown, although c-Fos has been implicated in transcriptional regulation of prodynorphin in dorsal horn neurons for persistent pain sensitization [62, 63].

The functional studies of pERK have greatly benefited from specific MEK inhibitors PD98059 and U0126. The degree of pERK suppression by MEK inhibitors can be readily confirmed by checking pERK levels. Using these inhibitors, accumulating evidence shows pERK in dorsal horn neurons is required for the induction of central sensitization, including behavioral indication of central sensitization such as second phase pain response to formalin
$[15,18]$ and capsaicin-induced secondary mechanical allodynia [43], and electrophysiological indication of central sensitization such as windup [64] and long-term potentiation in spinal cord neurons [65]. pERK induces central sensitization via increasing the activity of excitatory glutamate receptors (AMPA and NMDA) [66] and suppressing the activity of inhibitory potassium channels (Kv4.2) [67] in dorsal horn neurons (Fig. 3).

pERK is also important for the maintenance of central sensitization (Fig. 3). Upon activation, pERK is translocated to the nucleus of dorsal horn neurons, activating the transcriptional factor CREB that is critical for long-term neuronal plasticity [14]. ERK activation is essential for CREB phosphorylation in spinal cord dorsal horn neurons after noxious stimulation $[12,43]$ and during LTP induction [65]. However, unilateral noxious stimulation also induces CREB phosphorylation in the contralateral dorsal horn [12], which should not be mediated by ERK, given that pERK expression is unilateral. Other signal pathways, such as the PKA pathway and CaMK pathway may be involved in this contralateral induction of pCREB. CREB is likely to regulate many CRE-containing genes in dorsal horn neurons such as c-fos, Cox-2, zif-268, neurokinin-1, prodynorphin, TrkB and $n N O S$ [68]. Intrathecal delivery of MEK inhibitor has been shown to suppress inflammation-induced upregulation of c-Fos, prodynorphin, and NK-1 in superficial dorsal horn neurons $[43,52]$. Furthermore, intrathecal injection of MEK inhibitor can reverse inflammatory pain [35, 52, 53],

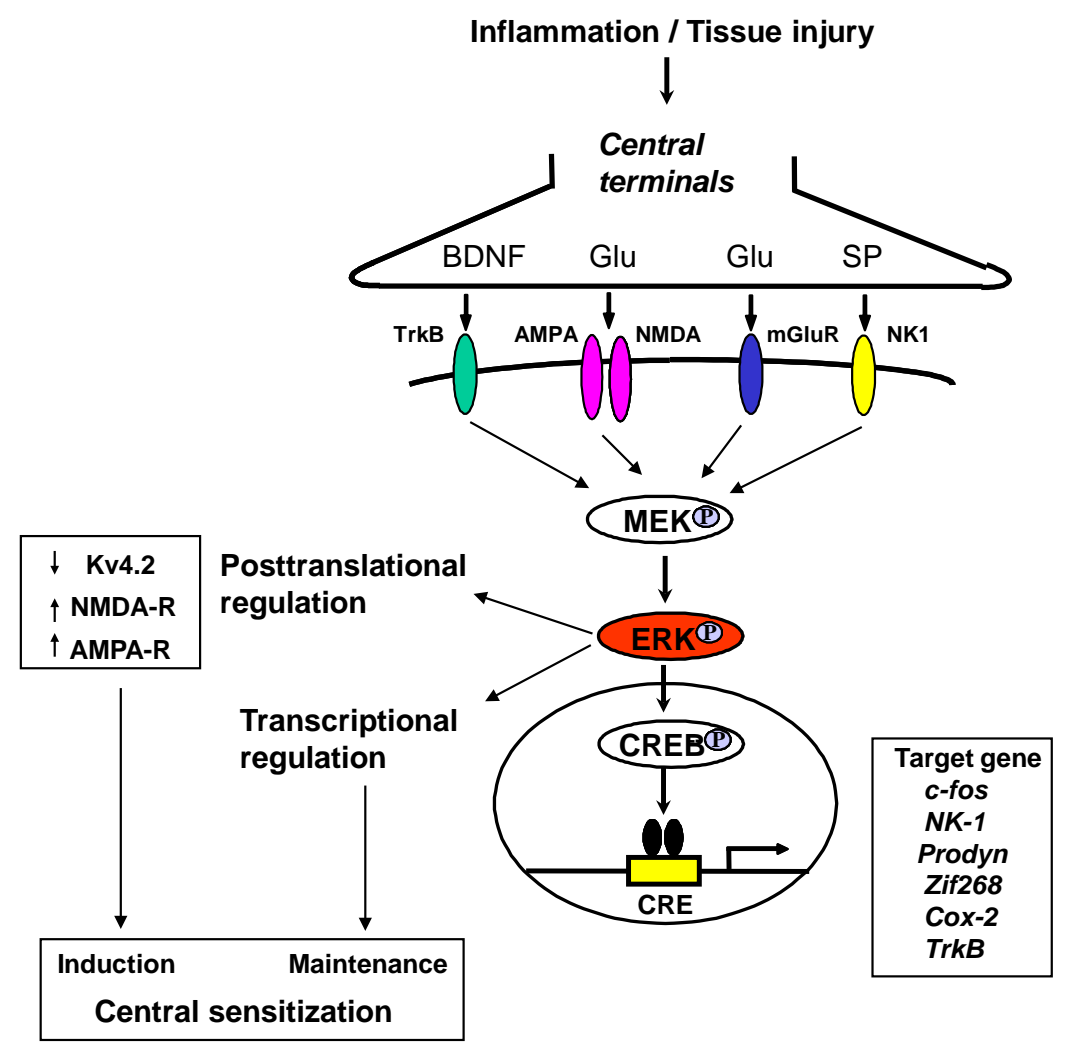

Fig. (3). Schematic of ERK-mediated central sensitization in spinal cord dorsal horn neurons. Tissue injury or inflammation induces release of neutrotransmitters such as glutamate (Glu) and neuromodulators such as brain-derived growth factor (BDNF) and substance P (SP), activating their corresponding receptors in postsynaptic neurons. Activation of these receptors results in ERK phosphorylation in dorsal horn neurons via MEK phosphorylation. pERK induces central sensitization by rapid posttranslational regulation, such as increasing the activity of AMPA and NMDA receptors and suppressing the activity of potassium channels Kv4.2. pERK also maintains central sensitization by transcriptional regulation, such as CREB-mediated induction of multiple target genes in dorsal horn neurons. 
supporting a role of ERK in the maintenance of central sensitization.

\section{CONCLUDING REMARKS}

It is extremely important for pain research to find markers for nociception/injury -induced neuronal activation and central sensitization. Both c-Fos and pERK are good markers for nociception-induced neuronal activation in the spinal cord dorsal horn, because they can be easily detected and quantified by immunohistochemistry. However, c-Fos and pERK differ in many ways (Table 1). pERK expression is more dynamic with rapid induction, various cellular and subcellular localization, close correlation to pain behavior. Importantly, blocking pERK induction with specific inhibitors can suppress injury-induced central sensitization and pain hypersensitivity. Thus, pERK is a better marker than c-Fos for central sensitization, despite the fact that cFos has been extensively used for twenty years as a pain marker.

\section{ACKNOWLEDGEMENTS}

This work was supported by NIH grants DE17794, NS54932, and TW7180 and National Natural Science Foundation of China (NSFC) 30528019 to R.-R.J, and NSFC 30500153 and Natural Science Research Program of Jiangsu Province $05 \mathrm{KJB} 180100$ to Y.-J.G.

\section{REFERENCES}

[1] Greenberg ME, Ziff EB, Greene LA. Stimulation of neuronal acetylcholine receptors induces rapid gene transcription. Science 1986; 234: 80-3.

[2] Rauscher FJ, 3rd, Sambucetti LC, Curran T, Distel RJ, Spiegelman BM. Common DNA binding site for fos protein complexes and transcription factor AP-1. Cell 1988; 52: 471-80.

[3] Naranjo JR, Mellstrom B, Achaval M, Lucas JJ, Del Rio J, Sassone-Corsi P. Co-induction of jun B and c-fos in a subset of neurons in the spinal cord. Oncogene 1991; 6: 223-7.

[4] Morgan JI, Cohen DR, Hempstead JL, Curran T. Mapping patterns of $\mathrm{c}$-fos expression in the central nervous system after seizure. Science 1987; 237: 192-7.

[5] Hunt SP, Pini A, Evan G. Induction of c-fos-like protein in spinal cord neurons following sensory stimulation. Nature $1987 ; 328$ : 632-4.

[6] Bullitt E, Lee CL, Light AR, Willcockson H. The effect of stimulus duration on noxious-stimulus induced c-fos expression in the rodent spinal cord. Brain Res 1992; 580: 172-9.

[7] Coggeshall RE. Fos, nociception and the dorsal horn. Prog neurobiol 2005; 77: 299-352

[8] Harris JA. Using c-fos as a neural marker of pain. Brain Res Bull 1998; 45: 1-8.

[9] Presley RW, Menetrey D, Levine JD, Basbaum AI. Systemic morphine suppresses noxious stimulus-evoked Fos protein-like immunoreactivity in the rat spinal cord. J Neurosci 1990; 10: 32335 .

[10] Traub RJ, Stitt S, Gebhart GF. Attenuation of c-Fos expression in the rat lumbosacral spinal cord by morphine or tramadol following noxious colorectal distention. Brain Res 1995; 701: 175-82.

[11] Widmann C, Gibson S, Jarpe MB, Johnson GL. Mitogen-activated protein kinase: conservation of a three-kinase module from yeast to human. Physiol Rev 1999; 79: 143-80.

[12] Ji RR, Rupp F. Phosphorylation of transcription factor CREB in rat spinal cord after formalin-induced hyperalgesia: relationship to cfos induction. J Neurosci 1997; 17: 1776-85.

[13] Ji RR, Woolf CJ. Neuronal plasticity and signal transduction in nociceptive neurons: implications for the initiation and maintenance of pathological pain. Neurobiol Dis 2001; 8: 1-10.

[14] Ji RR, Kohno T, Moore KA, Woolf CJ. Central sensitization and LTP: do pain and memory share similar mechanisms? Trends in neurosci 2003; 26: 696-705.
[15] Ji RR, Baba H, Brenner GJ, Woolf CJ. Nociceptive-specific activation of ERK in spinal neurons contributes to pain hypersensitivity. Nat Neurosci 1999; 2: 1114-9.

[16] Ji RR. Mitogen-activated protein kinases as potential targets for pain killers. Curr Opin Investig Drugs 2004; 5: 71-5.

[17] Kawasaki Y, Kohno T, Ji RR. Different effects of opioid and cannabinoid receptor agonists on $\mathrm{C}$-fiber-induced extracellular signal-regulated kinase activation in dorsal horn neurons in normal and spinal nerve-ligated rats. J Pharmacol Exp Ther 2006; 316: 601-7.

[18] Karim F, Wang CC, Gereau RW $4^{\text {th }}$. Metabotropic glutamate receptor subtypes 1 and 5 are activators of extracellular signalregulated kinase signaling required for inflammatory pain in mice. J Neurosci 2001; 21: 3771-9.

[19] Woolf CJ, Salter MW. Neuronal plasticity: increasing the gain in pain. Science 2000; 288: 1765-9.

[20] Ji RR, Gereau RW 4 ${ }^{\text {th }}$, Malcangio M, Strichartz G. MAP kinase and pain. Brain Res Rev 2008; [Epub ahead of print].

[21] Abbadie C, Honore P, Besson JM. Intense cold noxious stimulation of the rat hindpaw induces c-fos expression in lumbar spinal cord neurons. Neuroscience 1994; 59: 457-68.

[22] Traub RJ, Pechman P, Iadarola MJ, Gebhart GF. Fos-like proteins in the lumbosacral spinal cord following noxious and non-noxious colorectal distention in the rat. Pain 1992; 49: 393-403.

[23] Jinks SL, Simons CT, Dessirier JM, et al. C-fos induction in rat superficial dorsal horn following cutaneous application of noxious chemical or mechanical stimuli. Exp Brain Res 2002; 145: 261-9.

[24] Honore P, Buritova J, Besson JM. Carrageenin-evoked c-Fos expression in rat lumbar spinal cord: the effects of indomethacin Eur J Pharmacol 1995; 272: 249-59.

[25] Yi DK, Barr GA. The induction of Fos-like immunoreactivity by noxious thermal, mechanical and chemical stimuli in the lumbar spinal cord of infant rats. Pain 1995; 60: 257-65.

[26] Willcockson HH, Taylor-Blake B, Light AR. Induction of fos-like immunoreactivity by electrocutaneous stimulation of the rat hindpaw. Somatosens Mot Res 1995; 12: 151-61.

[27] Wei F, Vadakkan KI, Toyoda H, et al. Calcium calmodulinstimulated adenylyl cyclases contribute to activation of extracellular signal-regulated kinase in spinal dorsal horn neurons in adult rats and mice. J Neurosci 2006; 26: 851-61.

[28] Bester H, Beggs S, Woolf CJ. Changes in tactile stimuli-induced behavior and c-Fos expression in the superficial dorsal horn and in parabrachial nuclei after sciatic nerve crush. J Comp Neurol 2000; 428: 45-61

[29] Kosai K, Tateyama S, Ikeda T, Uno T, Nishimori T, Takasaki M MK-801 reduces non-noxious stimulus-evoked Fos-like immunoreactivity in the spinal cord of rats with chronic constriction nerve injury. Brain Res 2001; 910: 12-8.

[30] Molander C, Hongpaisan J, Persson JK. Distribution of c-fos expressing dorsal horn neurons after electrical stimulation of low threshold sensory fibers in the chronically injured sciatic nerve. Brain Res 1994; 644: 74-82.

[31] Hao S, Mata M, Wolfe D, et al. Gene transfer of glutamic acid decarboxylase reduces neuropathic pain. Ann Neurol 2005; 57 914-8.

[32] Wang H, Dai Y, Fukuoka T, et al. Enhancement of stimulationinduced ERK activation in the spinal dorsal horn and gracile nucleus neurons in rats with peripheral nerve injury. Eur J Neurosci 2004; 19: 884-90.

[33] Ma QP, Woolf CJ. Basal and touch-evoked fos-like immunoreactivity during experimental inflammation in the rat. Pain 1996; 67: 307-16.

[34] Wei F, Dubner R, Ren K. Dorsolateral funiculus-lesions unmask inhibitory or disfacilitatory mechanisms which modulate the effects of innocuous mechanical stimulation on spinal Fos expression after inflammation. Brain Res 1999; 820: 112-6.

[35] Cruz CD, Neto FL, Castro-Lopes J, McMahon SB, Cruz F. Inhibition of ERK phosphorylation decreases nociceptive behaviour in monoarthritic rats. Pain 2005; 116: 411-9.

[36] Neumann S, Braz JM, Skinner K, Llewellyn-Smith IJ, Basbaum AI. Innocuous, not noxious, input activates PKCgamma interneurons of the spinal dorsal horn via myelinated afferent fibers. J Neurosci 2008; 28: 7936-44.

[37] Draisci G, Iadarola MJ. Temporal analysis of increases in c-fos, preprodynorphin and preproenkephalin mRNAs in rat spinal cord Brain Res Mol Brain Res 1989; 6: 31-7. 
[38] Williams S, Evan GI, Hunt SP. Changing patterns of c-fos induction in spinal neurons following thermal cutaneous stimulation in the rat. Neuroscience 1990; 36: 73-81.

[39] Dai Y, Iwata K, Fukuoka T, et al. Phosphorylation of extracellular signal-regulated kinase in primary afferent neurons by noxious stimuli and its involvement in peripheral sensitization. J Neurosci 2002; 22: 7737-45.

[40] Zhuang ZY, Xu H, Clapham DE, Ji RR. Phosphatidylinositol 3kinase activates ERK in primary sensory neurons and mediates inflammatory heat hyperalgesia through TRPV1 sensitization. J Neurosci 2004; 24: 8300-9.

[41] Chi SI, Levine JD, Basbaum AI. Peripheral and central contributions to the persistent expression of spinal cord fos-like immunoreactivity produced by sciatic nerve transection in the rat. Brain Res 1993; 617: 225-37.

[42] Zhuang ZY, Gerner P, Woolf CJ, Ji RR. ERK is sequentially activated in neurons, microglia, and astrocytes by spinal nerve ligation and contributes to mechanical allodynia in this neuropathic pain model. Pain 2005; 114: 149-59.

[43] Kawasaki Y, Kohno T, Zhuang ZY, et al. Ionotropic and metabotropic receptors, protein kinase $\mathrm{A}$, protein kinase $\mathrm{C}$, and $\mathrm{Src}$ contribute to C-fiber-induced ERK activation and cAMP response element-binding protein phosphorylation in dorsal horn neurons, leading to central sensitization. J Neurosci 2004; 24: 8310-21.

[44] Yanagidate F, Strichartz GR. Bupivacaine inhibits activation of neuronal spinal extracellular receptor-activated kinase through selective effects on ionotropic receptors. Anesthesiology 2006; 104: 805-14

[45] Ji RR. Peripheral and central mechanisms of inflammatory pain, with emphasis on MAP kinases. Curr Drug Targets 2004; 3: 299303.

[46] Lever IJ, Pezet S, McMahon SB, Malcangio M. The signaling components of sensory fiber transmission involved in the activation of ERK MAP kinase in the mouse dorsal horn. Mol Cell Neurosci 2003; 24: 259-70.

[47] Catheline G, Le Guen S, Honore P, Besson JM. Are there longterm changes in the basal or evoked Fos expression in the dorsal horn of the spinal cord of the mononeuropathic rat? Pain 1999; 80: 347-57.

[48] Kingery WS, Agashe GS, Sawamura S, Davies MF, Clark JD, Maze M. Glucocorticoid inhibition of neuropathic hyperalgesia and spinal Fos expression. Anesth Analg 2001; 92: 476-82.

[49] Lee WT, Sohn MK, Park SH, Ahn SK, Lee JE, Park KA. Studies on the changes of c-fos protein in spinal cord and neurotransmitter in dorsal root ganglion of the rat with an experimental peripheral neuropathy. Yonsei Med J 2001; 42: 30-40.

[50] Hunter JC, Woodburn VL, Durieux C, Pettersson EK, Poat JA, Hughes J. c-fos antisense oligodeoxynucleotide increases formalininduced nociception and regulates preprodynorphin expression. Neuroscience 1995; 65: 485-92.

[51] Ibrahim MM, Mata HP, Chawla M, Lai J, Porreca F, Malan TP Jr. Allodynia and hyperalgesia produced by specific inhibition of spinal c-fos expression: lack of correlation with dynorphin content. J Pain 2001; 2: 241-9.

[52] Ji RR, Befort K, Brenner GJ, Woolf CJ. ERK MAP kinase activation in superficial spinal cord neurons induces prodynorphin and NK-1 upregulation and contributes to persistent inflammatory pain hypersensitivity. J Neurosci 2002; 22: 478-85.
[53] Adwanikar H, Karim F, Gereau RW $4^{\text {th }}$. Inflammation persistently enhances nocifensive behaviors mediated by spinal group I mGluRs through sustained ERK activation. Pain 2004; 111: 12535.

[54] Yu YQ, Chen J. Activation of spinal extracellular signalingregulated kinases by intraplantar melittin injection. Neurosci Lett 2005; 381: 194-8.

[55] Pang XY, Liu T, Jiang F, Ji YH. Activation of spinal ERK signaling pathway contributes to pain-related responses induced by scorpion Buthus martensi Karch venom. Toxicon 2008; 51: 9941007.

[56] Obata K, Yamanaka H, Kobayashi K, et al. Role of mitogenactivated protein kinase activation in injured and intact primary afferent neurons for mechanical and heat hypersensitivity after spinal nerve ligation. J Neurosci 2004; 24: 10211-22.

[57] Gillardon F, Beck H, Uhlmann E, et al. Inhibition of c-Fos protein expression in rat spinal cord by antisense oligodeoxynucleotide superfusion. Eur J Neurosci 1994; 6: 880-4.

[58] Huang W, Simpson RK, Jr. Antisense of c-fos gene attenuates Fos expression in the spinal cord induced by unilateral constriction of the sciatic nerve in the rat. Neurosci lett 1999; 263: 61-4.

[59] Sugiyo S, Yonehara N, Appenteng K, Nokubi T, Shigenaga Y, Takemura M. Effects of intrathecal c-fos antisense oligodeoxynucleotide on adjuvant-induced thermal hyperalgesia. Exp Brain Res 2001; 140: 198-205.

[60] Wu SX, Wang W, Wang YY, Ni TS, Li YQ, Yew DT. C-fos antisense oligodeoxynucleotide decreases subcutaneous bee venom injection-induced nociceptive behavior and fos expression in the rat. Neurosignals 2002; 11: 224-30.

[61] Hou WY, Shyu BC, Chen TM, Lee JW, Shieh JY, Sun WZ. Intrathecally administered $\mathrm{c}$-fos antisense oligodeoxynucleotide decreases formalin-induced nociceptive behavior in adult rats. Eur J Pharmacol 1997; 329: 17-26.

[62] Noguchi K, Kowalski K, Traub R, Solodkin A, Iadarola MJ, Ruda MA. Dynorphin expression and Fos-like immunoreactivity following inflammation induced hyperalgesia are colocalized in spinal cord neurons. Brain Res Mol Brain Res 1991; 10: 227-33.

[63] Dubner R, Ruda MA. Activity-dependent neuronal plasticity following tissue injury and inflammation. Trends Neurosci 1992; 15: 96-103.

[64] Fukui T, Dai Y, Iwata $\mathrm{K}$, et al. Frequency-dependent ERK phosphorylation in spinal neurons by electric stimulation of the sciatic nerve and the role in electrophysiological activity. Mol Pain 2007; 3: 18 .

[65] Xin WJ, Gong QJ, Xu JT, et al. Role of phosphorylation of ERK in induction and maintenance of LTP of the C-fiber evoked field potentials in spinal dorsal horn. J Neurosci Res 2006; 84: 934-43.

[66] Kohno T, Wang H, Amaya F, et al. Bradykinin enhances AMPA and NMDA receptor activity in spinal cord dorsal horn neurons by activating multiple kinases to produce pain hypersensitivity. J Neurosci 2008; 28: 4533-40.

[67] $\mathrm{Hu} \mathrm{HJ}$, Carrasquillo Y, Karim F, et al. The kv4.2 potassium channel subunit is required for pain plasticity. Neuron 2006; 50: $89-100$.

[68] Lonze BE, Ginty DD. Function and regulation of CREB family transcription factors in the nervous system. Neuron 2002; 35: 60523.

This is an open access article licensed under the terms of the Creative Commons Attribution Non-Commercial License (http://creativecommons.org/licenses/by-nc/3.0/) which permits unrestricted, non-commercial use, distribution and reproduction in any medium, provided the work is properly cited. 